\title{
Experiência no Programa Institucional de Bolsas de Iniciação à Docência (PIBID): Desenvolvimento do Raciocínio Lógico e Algoritmo na Educação Básica
}

\author{
Árllon C. Lima, Decíola F. de Sousa \\ Instituto Ciberespacial - Universidade Federal Rural da Amazônia (UFRA) \\ Av. Presidente Tancredo Neves, 2501. 66077-901. Belém-PA-Brasil. \\ arlionlima@yahoo.com.br, deciola.sousa@ufra.edu.br
}

\begin{abstract}
This article aims to present the knowledge and improvement acquired in teaching through the PIBID's project (Institutional Program of Teaching Initiation's Scholarship) that through a course to teach the constructions of algorithms, logic and the algorithm itself. This job was done at E.E.E.F.M. Barão de Igarapé Miri School in Belém. It was tried to achieve a great performance and understanding from the students about the subject that was taught, practicing the knowledge learned through the pseudolanguage "Portugol" and exercises related with the their daily, aiming to improve the way the subjects were taught.
\end{abstract}

Resumo. $O$ artigo tem como objetivo apresentar a experiência adquirida por um bolsista do Programa Institucional de Bolsas de Iniciação à Docência (PIBID) através de um curso realizado na escola E.E.E.F.M. Barão de Igarapé Miri em Belém-PA, destinado ao ensino da construção de algoritmo. Trabalhou-se o pensamento computacional, o raciocínio lógico e o próprio algoritmo, buscando-se alcançar o desempenho e compreensão dos alunos do conteúdo ministrado, colocando em prática os conhecimentos adquiridos por meio da utilização dos computadores da sala de informática na escola, através da pseudo-linguagem "Portugol" e de exercícios relacionados ao cotidiano, para facilitar o processo de ensino e aprendizagem.

\section{Introdução}

São várias as maneiras de construção do conhecimento com as mais variadas formas didáticas e ferramentas utilizadas, muitas delas adaptadas para disseminação do conteúdo a ser ministrado em sala de aula. E em um mundo cada vez mais tecnológico o ensino pode se tornar mais dinâmico, criativo e produtivo tanto para os alunos quanto para os professores. Em escolas públicas, por exemplo, com a inserção da sala de informática os alunos têm a possibilidade de englobar, através do auxílio do computador, diversas matérias em diferentes áreas do conhecimento de uma forma mais ampla, dinâmica e interdisciplinar, o que torna o computador uma ferramenta importante para a construção do conhecimento dos alunos.

Diante disso, o ambiente informatizado na perspectiva construcionista propõe ao aluno construir e reconstruir o seu conhecimento por meio das informações do mundo exterior. O computador passa a ser a ferramenta educacional que possibilita a construção do conhecimento [Fugimoto 2009]. 


\section{CBIE-LACLO 2015}

Anais dos Workshops do IV Congresso Brasileiro de Informática na Educação (CBIE 2015)

Quando se trata de informática voltada ao processo de ensino e aprendizagem, deve-se levar em consideração não somente as ferramentas básicas que a máquina proporciona, mas também os princípios computacionais capazes de enriquecer a aprendizagem, servindo de base para diversas matérias de ensino, sendo utilizado enquanto instrumento para o processo de construção do conhecimento dos indivíduos.

A utilização de computadores na educação é muito mais diversificada, interessante e desafiadora, do que simplesmente a de transmitir informação ao aprendiz [Valente 1999]. O computador pode ser também utilizado para enriquecer ambientes de aprendizagem e auxiliar o aprendiz no processo de construção do seu conhecimento.

O Programa Institucional de Bolsas de Iniciação à Docência (PIBID), destinado aos discentes de Licenciatura em Computação da Universidade Federal Rural da Amazônia (UFRA), proporciona aos bolsistas a oportunidade de desenvolverem a prática docente, uma experiência de suma importância por serem futuros profissionais da educação em computação. Proporciona também para os alunos das escolas públicas a oportunidade de melhorar o desempenho escolar, assim como um maior conhecimento sobre a área de computação. Uma oportunidade de colaborar com o desenvolvimento da área de computação no país e na região norte, por meio de ações que desenvolvam a habilidade que consideramos a mais importante de um profissional de informática, a programação de computadores [Bezerra 2014].

Diante dos aspectos citados, considera-se importante a realização do curso sobre o desenvolvimento do pensamento lógico e algoritmo para alunos de escola pública por proporcionar contato com o computador, possibilitar diferentes maneiras de utilizá-lo e despertar o interesse e a criatividade dos alunos através de atividades relacionadas com os acontecimentos do dia a dia e com as matérias escolares.

O artigo apresenta a experiência do curso ministrado por bolsistas do PIBID para alunos do ensino médio de uma Escola Pública onde foi trabalhado a introdução ao raciocínio lógico; conceitos de algoritmo; estrutura sequencial e estrutura de seleção. As atividades realizadas com a construção dos algoritmos foram executadas nos computadores da escola, ferramenta importante nesse processo por ser o meio de concretização do que foi ensinado aos alunos através da Pseudo-linguagem "Portugol IDE”, uma plataforma simples e de fácil acesso [Noschang 2014].

O artigo na seção 2 apresenta trabalhos relacionados, na seção 3 detalha a metodologia aplicada no curso, na seção 4 apresenta a avaliação e a análise dos resultados, as considerações finais e trabalhos futuros na seção 5.

\section{Trabalhos Relacionados}

Uma ferramenta de construção de um jogo foi proposta por [França e Amaral 2012] que tinha como objetivo o aprendizado de conteúdos da Lógica de Programação considerando aspectos inerentes à concepção de interfaces educativas, favorecendo, assim, a aprendizagem do conteúdo tendo como público-alvo alunos do Ensino Médio da Educação Básica com a adoção de uma metodologia que considera aspectos estruturais, bem como os relativos ao processo de aprendizagem na construção das suas interfaces. Os autores afirmam que nos dias atuais, cada vez mais, torna-se evidente e necessário o ensino da Computação na Educação Básica, como forma de disseminação do pensamento algorítmico (computacional), a qualquer área de conhecimento, com o intuito também de estimular o desenvolvimento do raciocínio lógico e abstrato. 


\section{CBIE-LACLO 2015}

Anais dos Workshops do IV Congresso Brasileiro de Informática na Educação (CBIE 2015)

A experiência obtida no curso de introdução a algoritmo oferecido aos alunos do ensino médio de uma escola pública através do projeto Desenvolvendo a Lógica e Algoritmos na Escola é relatado por [Sousa 2013]. O curso foi desenvolvido através do Programa Institucional de Bolsas de Iniciação a Docência do curso de Licenciatura em Computação da Universidade Federal Rural da Amazônia (UFRA), teve como objetivo ensinar e desenvolver com os alunos do ensino médio de uma escola pública do estado na região metropolitana de Belém exercícios de lógica e de algoritmos básicos, proporcionando oportunidades de aprender e vivenciar o ensino e a prática dos conceitos de lógica e algoritmo. A autora relata que o aspecto central da computação é a habilidade do aluno sistematizar a solução de um problema através de um raciocínio lógico e que, além disso, acredita-se que o desenvolvimento do raciocínio lógico no ensino médio motivará os alunos a permanecerem na Escola, no ingresso a um curso superior e ajudará nas disciplinas de programação.

Uma experiência obtida em uma oficina de introdução a programação oferecida aos alunos do ensino médio da região do Vale do Mamanguape da Paraíba é descrita por [Marques et al. 2011]. A oficina teve duração total de 16 horas, divididas em 4 aulas com 4 horas de duração, focou na linguagem de programação Python e utilizou jogos como fator motivacional para atrair os alunos e aumentar o seu interesse para o conteúdo apresentado e para a área de computação. Além dos jogos utilizados, utilizaram outras práticas para o ensino de programação. O objetivo da oficina foi o de ensinar programação para os alunos do ensino médio, utilizando como fator de motivação jogos digital, algo com que os alunos convivem com frequência.

Existem outros projetos com pensamento computacional e Lógica de Programação que atuam no ensino superior como o que [Barcelos 2013] explora em seu projeto de pesquisa as relações entre o conhecimento matemático prévio dos alunos ingressantes em cursos superiores na área de Computação e o desenvolvimento de habilidades e competências básicas para o domínio da tecnologia, denominadas como pensamento computacional, e as possíveis interações entre ambos no contexto de uma oficina de desenvolvimento de jogos digitais, elaborada e oferecida dentro da estrutura curricular de um curso técnico em Informática. Para o autor a Lógica de Programação é indispensável para a continuidade com sucesso dos estudos na área. Dessa forma, identificar como os novos conhecimentos em programação se ancoram nos conceitos matemáticos já presentes (ou que deveriam estar presentes) pode constituir-se em uma contribuição para aperfeiçoar o ensino de Computação e Matemática.

De modo geral, os trabalhos evidenciam a importância da lógica de programação e do ensino de algoritmo para alunos do ensino médio, além de compartilhar aspectos comuns e o objetivo de tornar a aprendizagem mais atrativa.

\section{Metodologia}

O curso de 24 horas foi realizado na escola E.E.E.F.M. Barão de Igarapé Miri (localizada em um bairro de periferia em Belém-PA), divulgado pelos bolsistas junto ao supervisor na escola para os alunos do $1^{\circ}, 2^{\circ}$ e $3^{\circ}$ ano do ensino médio do turno da manhã, o curso foi realizado no contra turno com 4 horas de aulas na semana. Pelo grau de complexidade e baseado em experiências anteriores, o curso é adequado para alunos do ensino médio. 
Das 30 vagas disponíveis para o curso na escola obteve-se 36 inscritos, vinte e um alunos participaram do curso, o que corresponde a 63,3\% dos inscritos. Dos vinte e um participantes, dezoito tiveram presença maior ou igual a $75 \%$ e três menor que $75 \%$ durante o curso, conforme a Tabela 1.

Tabela 1: Vagas disponíveis, quantidade de alunos inscritos, participantes e presença.

\begin{tabular}{|c|c|c|c|}
\hline $\begin{array}{c}\text { VAGAS } \\
\text { DISPONÍVEIS }\end{array}$ & $\begin{array}{c}\text { ALUNOS } \\
\text { INSCRITOS }\end{array}$ & $\begin{array}{c}\text { ALUNOS } \\
\text { PARTICIPANTES }\end{array}$ & $\begin{array}{c}\text { PRESENÇA } \\
(\%)\end{array}$ \\
\hline 30 & 36 & 21 & $18>=75 \%$ \\
\cline { 3 - 4 } 30 & 36 & $3<75 \%$ \\
\hline
\end{tabular}

No início do curso se realizou uma avaliação diagnostica, um pré-teste conforme os livros adotados pela Escola, como forma de verificar o grau de conhecimento, possibilitando analisar e identificar as dificuldades dos alunos nas matérias de matemática, português e lógica, conteúdos importantes para a construção do algoritmo. Assim foi possível buscar formas adequadas e coerentes de ministrar as aulas em que os alunos pudessem assimilar e concretizar na prática o que foi ensinado.

Realizou-se atividades de desenvolvimento de raciocínio lógico através de objetos de aprendizagem, responsáveis por estimular, organizar e ordenar o pensamento dos alunos da escola, utilizando-se de situações do cotidiano para facilitar o processo de ensino e aprendizagem. O desenvolvimento do pensamento lógico para organização do pensamento foi importante para que os alunos da escola começassem a construção dos algoritmos, já que um algoritmo é uma sequência de passos ordenados tendo como principal objetivo a resolução de problemas.

Mesmo para os graduandos em Licenciatura em Computação as disciplinas de algoritmo são complexas, principalmente pela dificuldade de utilizar o pensamento lógico, conceitos matemáticos e interpretação textual. Pensando nisso, buscou-se formas de adaptar o conteúdo do curso para que os alunos da escola conseguissem por si próprios assimilar e desenvolver suas capacidades através do que foi ensinado, planejando as aulas de acordo com a realidade e necessidades dos alunos, de forma simples, participativa e explicativa, fazendo relação dos conteúdos com o cotidiano dos mesmos para facilitar o processo de ensino e aprendizagem.

Ensinou-se aos alunos os comados básicos de algoritmo como "início", tipos de variáveis (real, inteiro, texto e caractere), "ler", "escrever" e "fim". E duas das estruturas existentes, a Estrutura Sequencial e a Estrutura de Seleção. [Furtado e Araújo 2013] designam a Estrutura Sequencial como a "estrutura que garante a execução de um comando após o outro", ou seja, apresenta uma sequência ordenada de passos. Uma atividade dessa estrutura realizada pelos alunos foi calcular a soma entre dois ou mais números.

Para a Estrutura de Seleção, [Furtado e Araújo 2013] colocam como uma estrutura que permite a escolha entre duas alternativas possíveis, ou seja, é uma construção condicional em que pode ter diferentes resultados. Nessa estrutura é acrescentado os comando "se", "entao", "senao" e "fimse". Um exemplo que os alunos realizaram foi a soma de dois números, calcular a média e mostrar a mensagem de aprovado ou reprovado. 


\section{CBIE-LACLO 2015}

Anais dos Workshops do IV Congresso Brasileiro de Informática na Educação (CBIE 2015)

Os exercícios desenvolvidos durante o curso foram elaborados de acordo com a capacidade, conhecimento, contexto e realidade dos alunos. Foram de níveis fácil, médio e difícil, com as matérias de lógica, matemática e interpretação textual (Português), buscando despertar o interesse e instigar a curiosidade, deixando os exercícios mais simples e adequados possíveis para uma boa compreensão, além de promover a interação entre eles com atividades grupais.

Todos os exercícios propostos aos alunos foram realizados de forma a atender as necessidades dos mesmos e o objetivo do curso. Os exercícios foram realizados sem que os bolsistas ajudassem os alunos durante a resolução, ou seja, deixando que eles tivessem suas próprias tomadas de ação e decisão, contribuindo assim para um melhor aprendizado.

A plataforma utilizada para construção do algoritmo o IDE (Integrated Development Environment) Portugol, foi instalada pelos bolsistas nos computadores da sala de informática da Escola em que se realizou o curso, sendo utilizada como meio de os alunos colocarem na prática o que estava sendo ensinado para construção de algoritmo. Essa plataforma é tida como raiz para se ensinar algoritmo, por ser uma plataforma simples e de fácil acesso, o Portugol tornou o processo de ensino e aprendizagem produtivo pela facilidade que os bolsistas tinham em utilizá-lo.

Os recursos didático-pedagógicos utilizados foram o datashow; computadores, importantes para a prática do que foi ensinado e pré-testes no início do curso e póstestes no final do curso com o conteúdo das matérias de matemática, português e lógica, os quais mensuraram o nível de conhecimento dos alunos para uma melhor adequação do curso. No final do curso os alunos realizaram uma avaliação da construção do algoritmo como forma de obter informações sobre o grau de conhecimentos adquiridos pelos alunos e mensurar os resultados positivos ou negativos. Os alunos da Escola tiveram a oportunidade de avaliar o curso e a atuação dos bolsistas.

Compreender a avaliação da aprendizagem como um recurso pedagógico útil e necessário para auxiliar cada educador e cada educando na busca e na construção de si mesmo e do seu melhor modo de ser na vida [Luckesi 2000]. Dessa forma podemos dizer que esse recurso é considerado de grande importância no processo de ensino e aprendizagem dos alunos, por possibilitar a eles e ao próprio profissional da educação uma melhor construção pessoal, social e consequentemente do conhecimento.

\section{Avaliação e analise dos resultados}

A avaliação se faz presente em vários aspectos do nosso cotidiano e se tornou um meio necessário no processo de ensino e aprendizagem, sendo uma maneira, por exemplo, de o professor fazer a análise do nível de aproveitamento de uma unidade ou de determinada parte do conteúdo e dessa forma tomar determinada ação em relação aos resultados de acordo com as dificuldades identificadas, buscando soluções para um melhor desenvolvimento de suas aulas.

São vários os critérios utilizados de como a avaliação pode ser aplicada. $\mathrm{Na}$ experiência realizada na escola utilizou-se a primeira avaliação no início do curso, préteste, como forma de identificar a capacidade e o grau de conhecimento dos alunos da escola, para que fosse possível analisar e identificar as dificuldades em lógica, matemática e português, importantes para o objetivo do curso, ou seja, para a construção do algoritmo, sendo possível buscar formas adequadas e coerentes de conduzir o curso. 


\section{CBIE-LACLO 2015}

Anais dos Workshops do IV Congresso Brasileiro de Informática na Educação (CBIE 2015)

A segunda avaliação foi realizada no final do curso, pós-teste, para mensurar os resultados positivos ou negativos obtidos.

Na primeira avaliação realizada com os alunos no início do curso, dezenove dos vinte e um alunos participantes realizaram a avaliação com o conteúdo de lógica, matemática e português, onde dezessete dos dezenove alunos que realizaram a avaliação tiraram nota maior ou igual a média 5 tanto em português como em matemática e somente dois com nota inferior a média, já em lógica apenas seis dos dezenove tiraram nota maior ou igual a média e treze menor.

Com os resultados obtidos, percebe-se que os alunos não possuem grandes dificuldades em português e em matemática, no entanto apresentam maiores dificuldades em lógica, conteúdo de grande importância para construção do algoritmo.

$\mathrm{Na}$ segunda avaliação, dos dezessete alunos que realizaram a avaliação treze tiraram nota maior ou igual a média 5 em português e quatro menor, quinze com nota maior ou igual a média em matemática e dois menor e quatorze com nota maior ou igual a média em lógica e somente três menor.

A Figura 1 apresenta uma comparação das duas avaliações realizadas durante o curso, uma no início e a outra no final, ilustrando o percentual de alunos que conseguiram ficar com a média 5 ou acima.

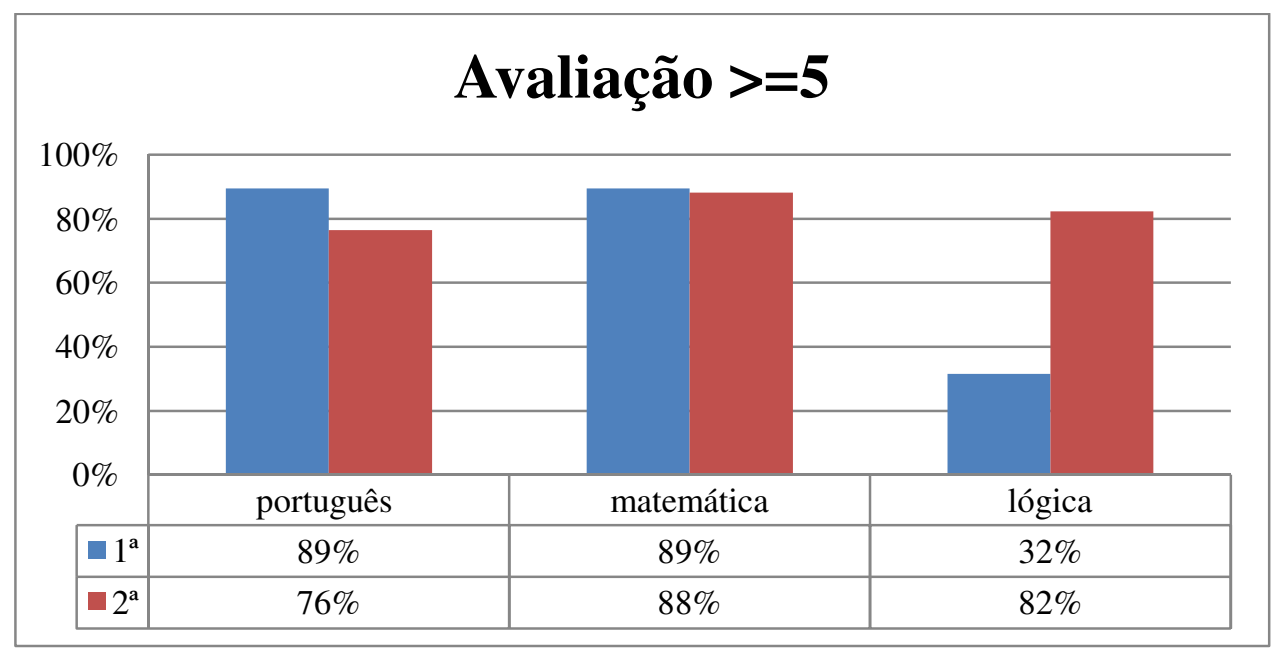

Figura 1. Resultado das duas avaliações realizadas com os alunos.

Os resultados da Figura 1 mostram que os alunos obtiveram um desempenho positivo na segunda avaliação, principalmente em lógica onde mais tinham dificuldades no início do curso, $82 \%$ dos alunos ficaram com a nota maior ou igual a 5 na segunda avaliação, ao contrário da primeira avaliação onde somente $32 \%$ dos alunos ficaram com a nota maior ou igual a 5 .

O desenvolvimento do raciocínio lógico contribuiu para que os alunos realizassem a avaliação da construção de algoritmo representada na Figura 2. 


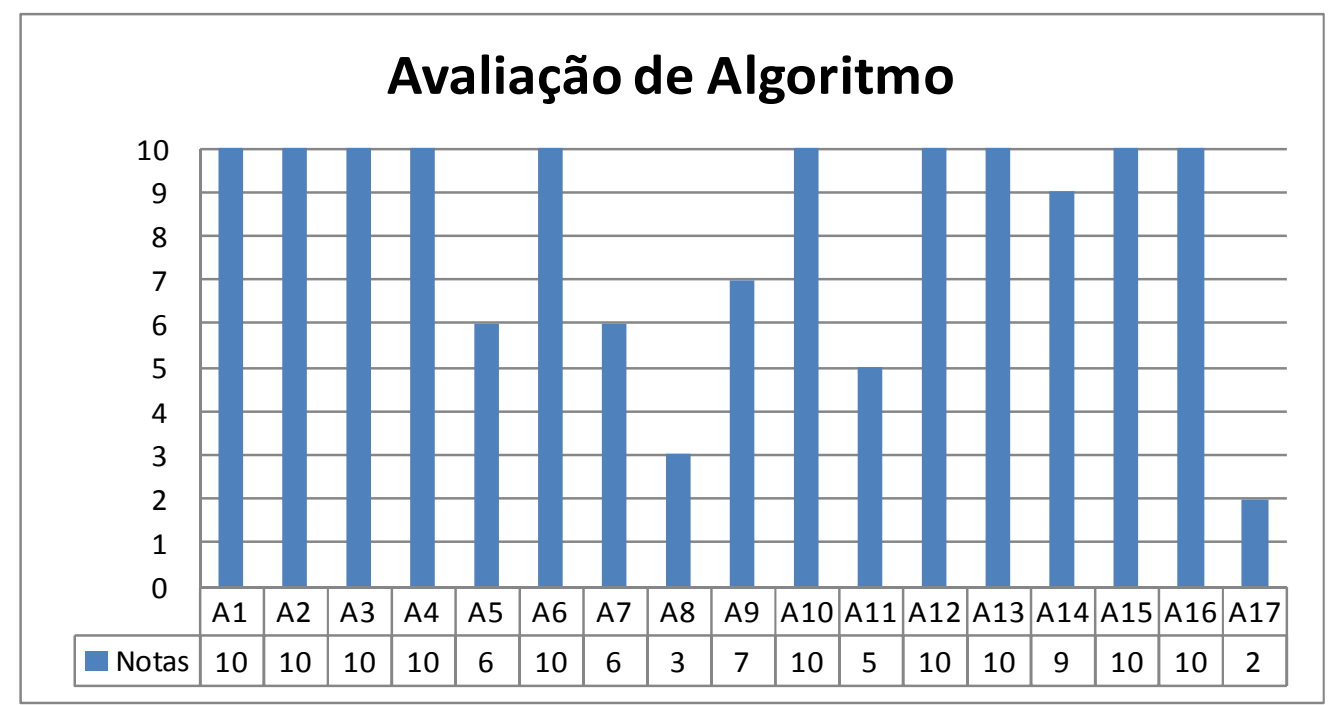

Figura 2: Avaliação dos alunos ( $A=$ =aluno) na construção de algoritmo.

As notas apresentadas Figura 2 demonstram que os alunos obtiveram notas relevantes na construção dos algoritmos utilizando o Portugol IDE, onde dez dos dezessete ficaram com nota máxima, ou seja, concluíram $100 \%$ da avaliação, pois conseguiram realizar por completo o algoritmo.

A Figura 3 apresenta o percentual de alunos em relação a média 5 na avaliação de algoritmo.

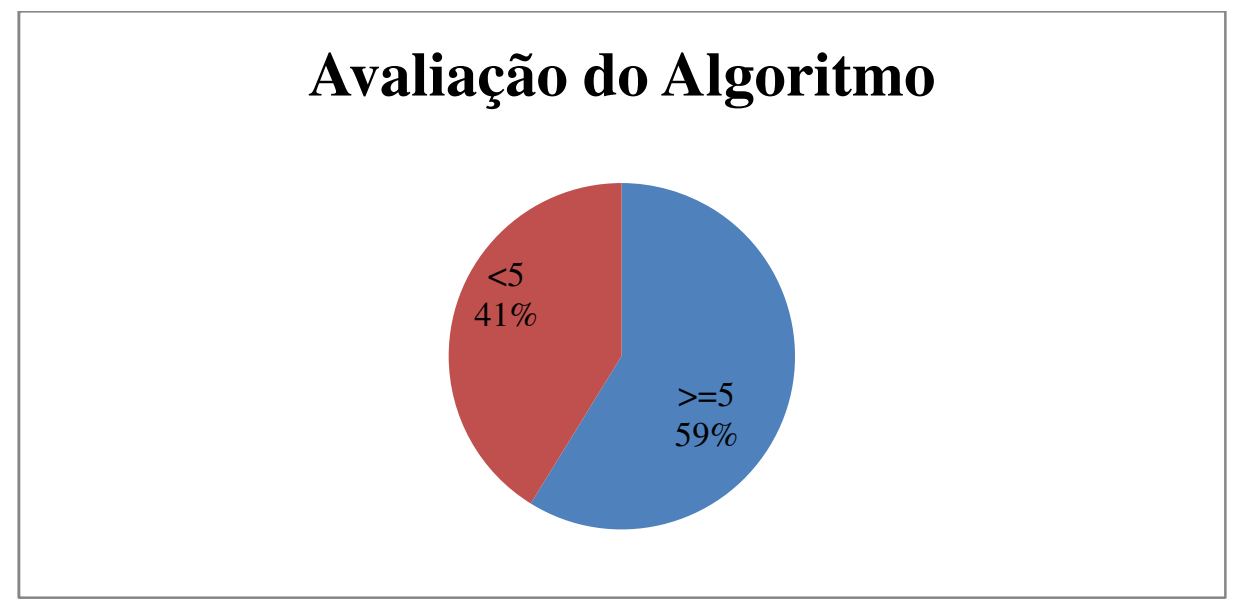

Figura 3: Resultado da avaliação de Algoritmo em relação a média 5.

Conforme a Figura 3, mais da metade dos alunos obtiveram notas acima da média 5 na construção de algoritmo. A avaliação da construção do algoritmo foi feita de forma individual, se considerando todos e qual quer comando válido realizado pelos alunos, mesmo que não conseguissem finalizar a questão.

Realizou-se com os alunos uma avaliação do curso ministrado, do conteúdo trabalhado e da relação do curso com as matérias da Escola, o resultado é apresentado na Figura 4. 
CBIE-LACLO 2015

Anais dos Workshops do IV Congresso Brasileiro de Informática na Educação (CBIE 2015)

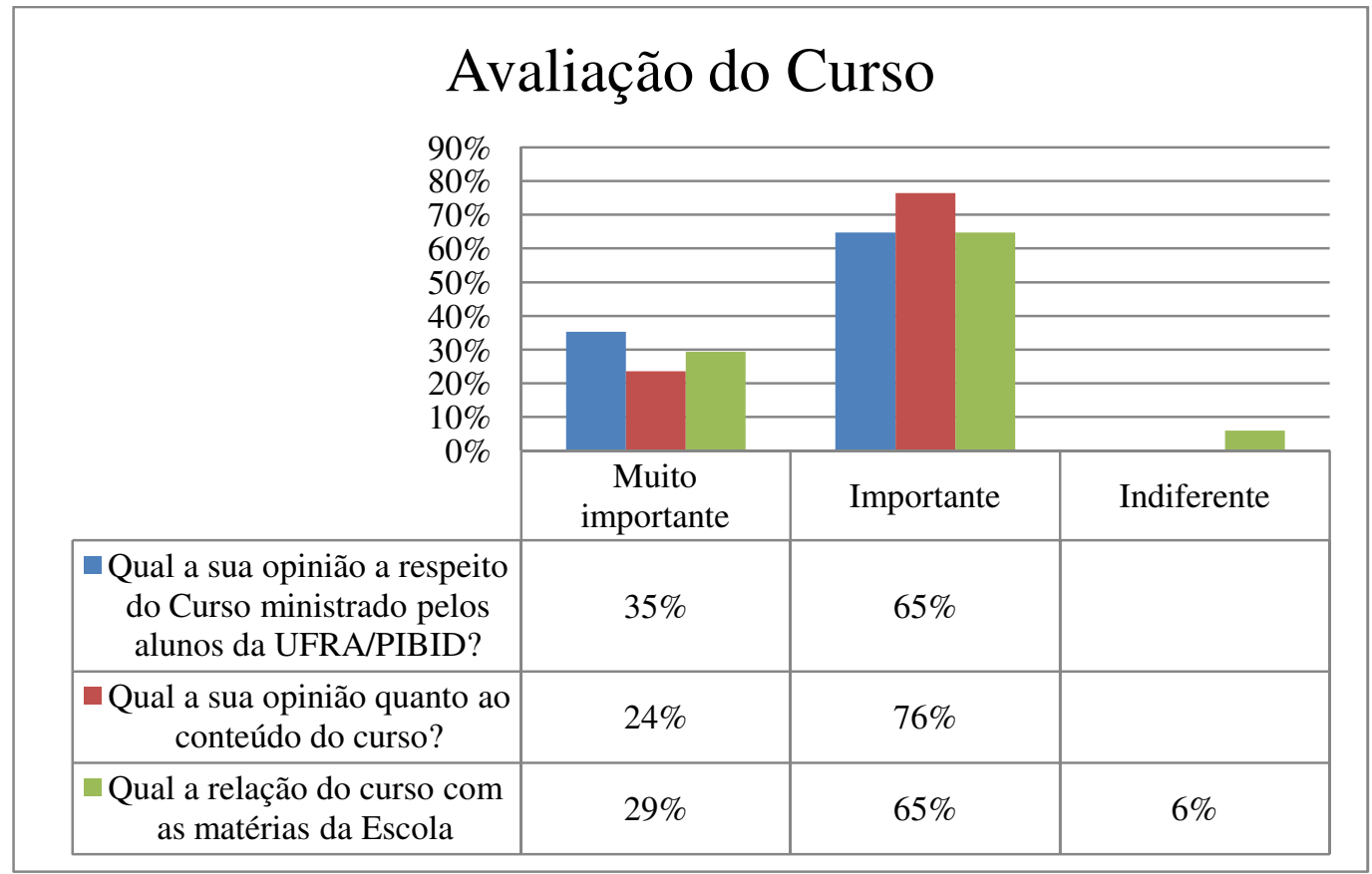

Figura 4: Resultado da avaliação do curso pelos alunos.

Conforme Figura 4, mais da metade dos alunos que realizaram o curso, avaliaram como importante, assim como o conteúdo trabalhado e a relação com as matérias da Escola.

O resultado da avaliação dos bolsistas pelos alunos está na Figura 5.

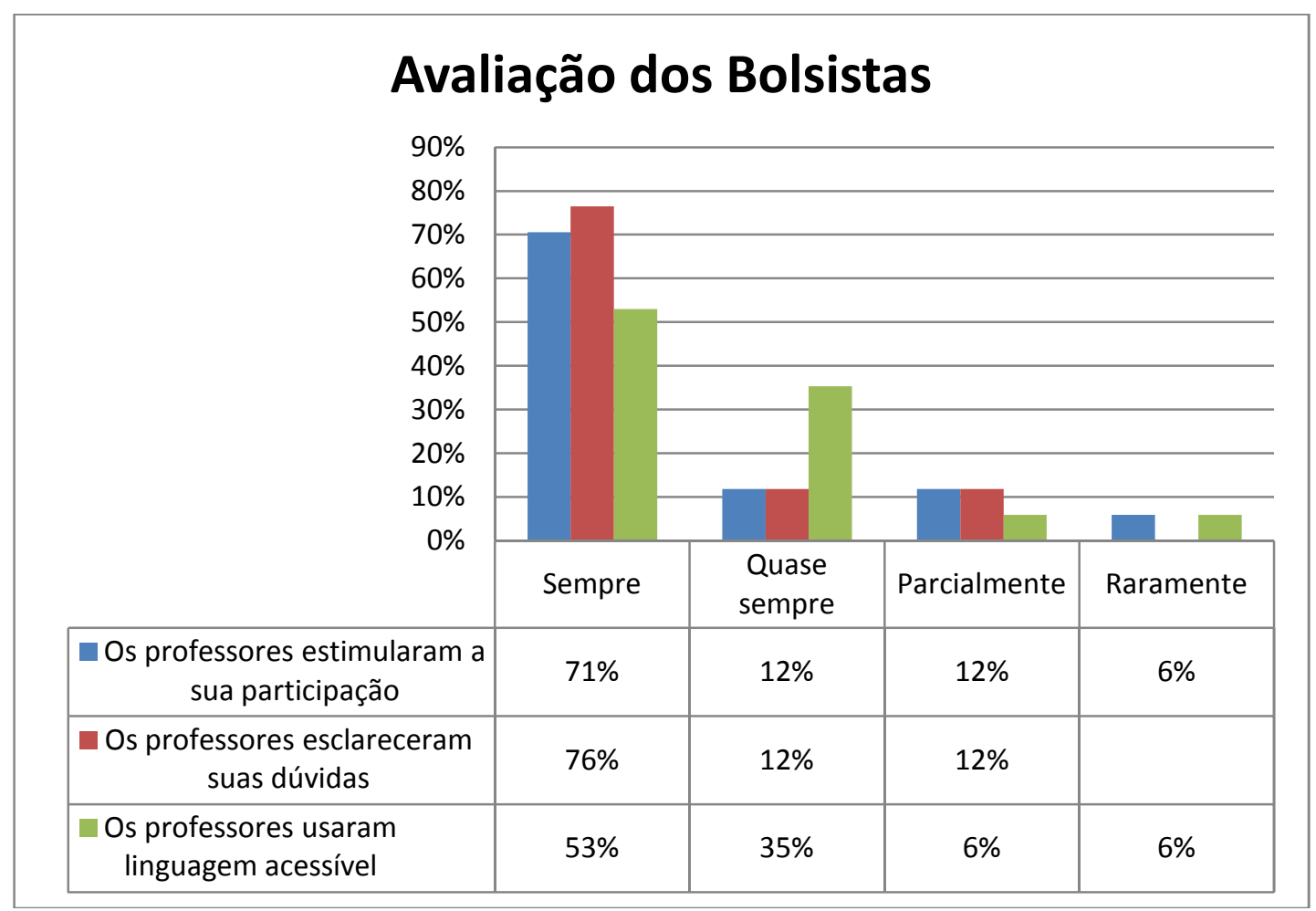

Figura 5: Resultado da avaliação dos bolsistas pelos alunos. 


\section{CBIE-LACLO 2015}

Anais dos Workshops do IV Congresso Brasileiro de Informática na Educação (CBIE 2015)

A avaliação da atuação dos bolsistas pelos alunos da Escola apresentada na Figura 5 é importante para o processo de aprendizagem dos futuros licenciados em computação, e assim melhorar a atuação nos próximos cursos, como foi detectado a linguagem utilizada pelos bolsistas precisa ser adequada ao nível da turma, porém é gratificante saber que mais da metade da turma tiveram as dúvidas esclarecidas e que os bolsistas conseguiram estimular a participação dos alunos.

O curso de introdução a Lógica e Algoritmo realizado na escola contribuiu para que os alunos pudessem na prática explorar novas formas de obter conhecimento com a utilização do computador. Por experiências anteriores, o curso está adequado para alunos do ensino médio, onde se teve maior participação e melhor compreensão por parte dos alunos da Escola.

\section{Considerações finais e trabalhos futuros}

O artigo apresentou o curso introdução a lógica e ao algoritmo realizado na Escola pública Barão de Igarapé Miri em um bairro de periferia da região metropolitana de Belém do Pará, onde possibilitou aos alunos da escola a oportunidade de entrarem em contato com o computador, aprendendo como essa ferramenta é importante e capaz de transformar o processo de ensino e aprendizagem, podendo se tornar mais criativo, dinâmico e atrativo.

Através do ensino da lógica e algoritmo, conseguiu-se alcançar os objetivos desejados, não só pelos resultados positivos e significativos em relação aos conteúdos de português, matemática e lógica de programação trabalhados, mas também pela possibilidade de mostrar aos alunos outras vertentes e diferentes formas de utilizar o computador e de como é importante para eles no processo de aprendizagem.

Ao término do curso, os professores da escola relataram a importância do curso na melhora do rendimento escolar dos alunos participantes, principalmente pelo fato de no curso se relacionar conteúdo de matemática, lógica e português, contribuindo para o crescimento dentro e fora do ambiente escolar, visto que, os alunos que participaram do curso com a frequência mínima exigida receberam certificado emitido pela UFRA e conseguiram se destacar ao serem selecionados em um programa chamado Jovem Aprendiz.

Os alunos da Escola e os bolsistas foram avaliados e avaliaram contribuindo para melhoria na aprendizagem e no projeto.

Infelizmente são grandes os desafios a se enfrentar nas escolas públicas em que geralmente os professores responsáveis pelos laboratórios de informática não são conhecedores da área, o que acaba desfavorecendo a utilização desse espaço de tanto valor para o ensino, consequentemente muitas escolas não utilizam essa ferramenta no processo de ensino e aprendizagem, seja pela resistência de muitos professores que não estão aptos a utilizá-lo, pela falta de um profissional qualificado na área de informática ou pela própria instituição escolar.

Contudo, o contato direto com ambiente escolar proporcionou aos bolsistas desenvolverem não só como futuros profissionais na área de educação em computação na educação básica, mas também enquanto ser humano, aprendendo a ter mais responsabilidades, apreendendo o verdadeiro valor de ensinar e de como proceder no processo de ensino e aprendizagem, tendo maior sensibilidade de como abordar os 


\section{CBIE-LACLO 2015}

Anais dos Workshops do IV Congresso Brasileiro de Informática na Educação (CBIE 2015)

conhecimentos obtidos de acordo com o contexto e realidade que os alunos da Escola Pública se encontram.

Como trabalho futuros, pretende-se com esses alunos, continuar o curso acrescentando a estrutura de repetição e a linguagem de programação Python.

\section{AGRADECIMENTOS}

O presente trabalho foi realizado com o apoio do Programa Institucional de Bolsa de Iniciação à Docência - PIBID, da CAPES - Coordenação de Aperfeiçoamento de Pessoal de Nível Superior - Brasil.

\section{REFERÊNCIAS BIBLIOGRÁFICAS}

Barcelos, T S. (2013). Relações entre o Pensamento Computacional e a Matemática através da construção de Jogos Digitais. In SBC - Proceedings of SBGames 2013. Cruzeiro do Sul, Brasil.

Bezerra, F. D. K. (2014). Programação de Computadores no Ensino Fundamental: Experiências com Logo e Scratch em Escola Pública. In: WEI - XXII Workshop sobre Educação em Computação, Brasília - DF, Brasil.

Fugimoto, Sonia M. A. (2009). O computador na escola: professor de educação básica e sua prática pedagógica. In: Seminário de Pesquisa PPE. Maringá - PR, Brasil.

Furtado, A., B. Araújo V. V. (2013). Curso de Construção de Algoritmos (com Java). Belém - PA, Brasil.

França, R. S.; Amaral, H. J. C. (2012). Proposta de um Jogo Eletrônico Educativo Aplicado ao Ensino da Lógica de Programação. Garanhuns - PE, Brasil.

Luckesi, C. (2000). O que é mesmo o ato de avaliar a aprendizagem? In: Revista Pátio Ano 3 - No 12 - Fevereiro/Abril. Porto alegre-RS, Brasil.

Marques, D. L.; Costa, L. F. S.; Silva, M. A. A.; Rebouças, A. D. D. S. (2011). Atraindo Alunos do Ensino Médio para a Computação: Uma Experiência Prática de Introdução a Programação utilizando Jogos e Python. In Anais do XXII SBIE - XVII WIE. Aracaju - SE, Brasil.

Noschang, Luiz F.; Pelz, F.; Jesus, E. A.; Raabe1, A. L. (2014). A Portugol Studio: Uma IDE para Iniciantes em Programação. In WEI - XXII Workshop sobre Educação em Computação, Brasília-DF, Brasil.

Sousa, D. F. (2013). Desenvolvendo a Lógica e Algoritmos no Ensino Médio. In II Congresso Brasileiro de Informática na Educação (CBIE 2013), XIX Workshop de Informática na Escola (WIE). UNICAMP, Cidade Universitária - Campinas-SP, Brasil.

Valente, J. A. (1999). Informática na Educação no Brasil: Análise e Contextualização Histórica. In O Computador na Sociedade do Conhecimento. Cidade de São Paulo SP, Brasil. 